\title{
All-metal Baird aromaticity
}

\author{
Dandan Chen, ${ }^{\text {ab }}$ Dariusz W. Szczepanik, ${ }^{\text {bc }}$ Jun Zhu*a and Miquel Solà*b
}

Received 00th January 20xx, Accepted 00th January 20xx

DOI: $10.1039 / x 0 x \times 00000 x$

\begin{abstract}
The Baird's rule has been applied to a large scope of organic molecular systems for rationalizing the aromaticity reversal in the lowest-lying triplet state. In this study, we demonstrate that the Baird's rule can be also extended to all-metal systems with $\sigma$ - and $\pi$-aromaticity.
\end{abstract}

Aromaticity is an important concept with ever-increasing attractiveness in the field of chemistry. Early development of aromaticity concept was limited to organic species, among which is benzene the most quintessential aromatic molecule. The well-known Hückel's rule states that in the singlet ground state ( $\left.\mathrm{S}_{0}\right)$, a $4 n+2$ monocyclic annulenic circuit exhibits aromaticity while a $4 n$ one exhibits anti-aromaticity. ${ }^{1}$ First proposed in 1972, the Baird's rule indicates the reversed aromatic character of the lowest-lying $\pi \pi^{*}$ triplet state $\left(T_{1}\right)$ in annulenes, ${ }^{2}$ with the same electron-counting rule as Möbius aromatic systems in the $S_{0}$ state $(4 n$ aromatic and $4 n+2$ antiaromatic). ${ }^{3}$ Application of Baird's rule has also been extended to Möbius molecules and transition state structures. ${ }^{4}$, 5 The Baird's rule is a useful tool for rationalizing excited-state properties and reactions, particularly for organic species. ${ }^{6-13}$ In contrast with extensive studies of Hückel-type all-metal aromaticity in the ground state, 14,15 Baird aromaticity of allmetal species has never been clearly proven in literature.

The first reported all-metal four- $\pi$-electron antiaromatic

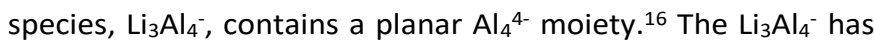

\footnotetext{
State Key Laboratory of Physical Chemistry of Solid Surfaces and Collaborative Innovation Center of Chemistry for Energy Materials (iChEM), Fujian Provincial Key Laboratory of Theoretical and Computational Chemistry and Department of Chemistry, College of Chemistry and Chemical Engineering, Xiamen University, 361005, Xiamen, China.E-mail: jun.zhu@xmu.edu.cn

b. Institute of Computational Chemistry and Catalysis and Department of Chemistry, University of Girona, C/ M. Aurèlia Capmany, 69, 17003 Girona, Catalonia, Spain. E-mail: miquel.sola@udg.edu

c. K. Guminski Department of Theoretical Chemistry, Faculty of Chemistry, Jagiellonian University, Gronostajowa, 2, 30-387 Kraków, Poland.

† Footnotes relating to the title and/or authors should appear here.

Electronic Supplementary Information (ESI) available: singlet-triplet energy gaps, molecular orbitals, optimized geometries, and Cartesian coordinates. See DOI: $10.1039 / x 0 \times x 00000 x$
}

two delocalized $\sigma$ molecular orbitals (MOs) consistent with the $\sigma$-radial $\left(\sigma_{\mathrm{rad}}\right)$ and $\sigma$-tangential $\left(\sigma_{\tan }\right)$ orbitals of $\mathrm{Al}_{4}{ }^{2-}$, which is also $\pi$-aromatic. ${ }^{16,}{ }^{17}$ With the additional two electrons, the naked $\mathrm{Al}_{4}^{4-}$ in the triplet state could be aromatic in one of the three aromatic systems ( $\sigma_{\mathrm{rad}}, \sigma_{\tan }$, and $\pi$ ) if it follows the Baird's rule. One of the key targets in our study is to explore the aromatic characters of the triplet $\mathrm{Al}_{4}{ }^{4-}$ as well as cationstabilized derivatives such as $\mathrm{Li}_{3} \mathrm{Al}_{4}^{-}$and related species like $\mathrm{Li}_{3} \mathrm{Ga}_{4}$ -

It has been shown that boron rings doped with beryllium cations, such as those in $\mathrm{Be}_{2} \mathrm{~B}_{6}$ and $\mathrm{Be}_{2} \mathrm{~B}_{7}{ }^{+}$, can achieve aromatic triplet ground states. ${ }^{18}$ Note that triplet ground state could also be achieved in osmapyridinium complexes due to adaptive aromaticity and substituent. ${ }^{19}$ The boron rings possess $4 \sigma$ and $6 \pi$ delocalized frameworks. It is clear that the $6 \pi$ system accounts for $\pi$-Hückel aromaticity, however, whether the $4 \sigma$ delocalized framework is associated with $\sigma$-Baird aromaticity remains undetermined.

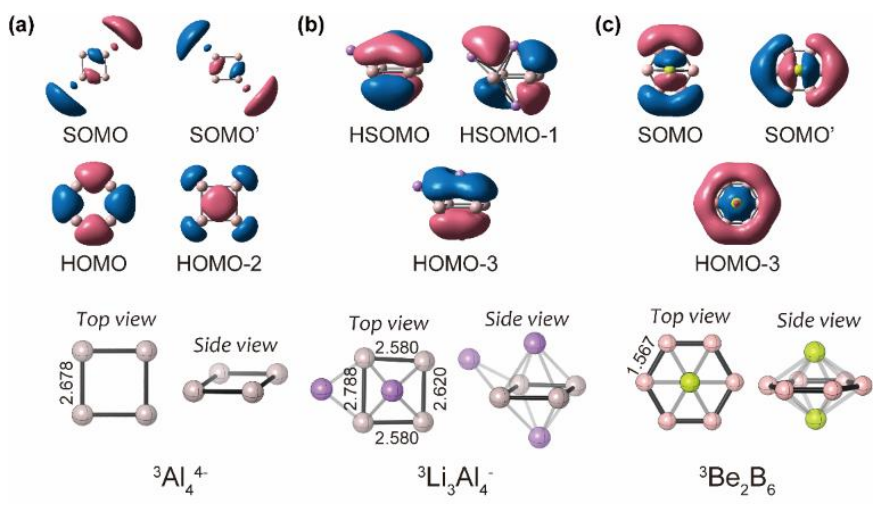

Fig. 1 Key molecular orbitals and optimized structures of ${ }^{3} \mathrm{Al}_{4}{ }^{4-}(\mathrm{a}),{ }^{3} \mathrm{Li}_{3} \mathrm{Al}_{4}{ }^{-}$(b), and ${ }^{3} \mathrm{Be}_{2} \mathrm{~B}_{6}$ (c). Isovalue for MOs: 0.03 a.u., except for the SOMOs of ${ }^{3} \mathrm{Al}_{4}{ }^{4-}(0.02$ a.u.). Bond lengths are given in $\AA$.

In this study, we applied the density functional theory (DFT) to evaluate the aromaticity of a series of all-metal clusters using state-of-the-art approaches including the electron density of delocalized bonds (EDDB), ${ }^{20}$ the multicenter index $(\mathrm{MCl})^{21-24}$ within the quantum theory of atoms in molecules (QTAIM), ${ }^{25,} 26$ 
and the iso-chemical-shielding surfaces (ICSS) method. ${ }^{27}$ Our results prove for the first time that the Baird's rule can be also applied to all-metal species.

In the $\mathrm{T}_{1}$ state, two unpaired electrons of $\mathrm{Al}_{4}{ }^{4-}$ occupy $\sigma \mathrm{MOs}$ instead of $\pi$ MOs while the optimized geometry is $D_{4 \mathrm{~h}}$ symmetric (Fig. 1a). We are aware that ${ }^{3} \mathrm{Al}_{4}{ }^{4-}$ is unstable with respect to $\mathrm{Al}_{4}^{-}+$three free $\mathrm{e}^{-}$. Although the electrons of the singly occupied molecular orbitals (SOMOs) of ${ }^{3} \mathrm{Al}_{4}^{4-}$ are unstable, both degenerate orbitals show the anti-bonding character of the $\sigma$-radial system. The formal electron counts suggest the triple aromaticity of ${ }^{3} \mathrm{Al}_{4}{ }^{4-}$ : Hückel aromaticity in the $\sigma_{\tan }$ system (2e in HOMO), Hückel aromaticity in the $\pi$ system (2e, see Fig. S1 in the ESI), and Baird aromaticity in the $\sigma_{\text {rad }}$ system (4e in SOMO, SOMO', and HOMO-2). Three lithium cations $\left(\mathrm{Li}^{+}\right)$can stabilize the extra electrons of $\mathrm{Al}_{4}{ }^{4-}$ by lowering the $\pi^{*}$ orbitals. Change of $\sigma$ to $\pi$ aromatic character due to coordination of counterions was already observed in $\mathrm{Mg}_{3}{ }^{2-}$ $/ \mathrm{NaMg}_{3}{ }^{-}$or $\mathrm{Na}_{2} \mathrm{Mg}_{3} .{ }^{28,}{ }^{29}$ Consequently, the unpaired electrons of ${ }^{3} \mathrm{Li}_{3} \mathrm{Al}_{4}-$ belong to the $\pi$ system including HSOMO, HSOMO-1, and HOMO-3 (Fig. 1b), indicating the possibility of $4 \pi$ Baird aromaticity. Similar to ${ }^{1} \mathrm{Li}_{3} \mathrm{Al}_{4}{ }^{-}$, the ${ }^{3} \mathrm{Li}_{3} \mathrm{Al}_{4}{ }^{-}$is also doubly aromatic in the $\sigma$ framework (Fig. S1).

The singlet-triplet energy gaps $\left(\Delta E_{\mathrm{ST}}=E_{\mathrm{T}}-E_{\mathrm{S}}\right)$ of $\mathrm{Al}_{4}{ }^{4-}$ and $\mathrm{Li}_{3} \mathrm{Al}_{4}^{-}$evaluated using the coupled cluster method $\operatorname{CCSD}(\mathrm{T})$ are $3.0 \mathrm{kcal} \mathrm{mol}^{-1}$ and $0.9 \mathrm{kcal} \mathrm{mol}^{-1}$, respectively (Table S1). The $\Delta E_{\mathrm{ST}}$ values are even less positive at the B3LYP level $\left(\mathrm{Al}_{4}{ }^{4-:}: 1.6 \mathrm{kcal}\right.$ $\left.\mathrm{mol}^{-1} ; \mathrm{Li}_{3} \mathrm{Al}_{4}:-0.5 \mathrm{kcal} \mathrm{mol}^{-1}\right)$. These small $\Delta E_{\mathrm{ST}}$ values could result from the extra stabilization by the Baird aromaticity in the triplet state. As an isoelectronic analogue of $\mathrm{Li}_{3} \mathrm{Al}_{4}^{-}$, the $\mathrm{Li}_{3} \mathrm{Ga}_{4}$ also has $4 \pi$-electrons. More interestingly, we found that $\mathrm{Li}_{3} \mathrm{Ga}_{4}$ has a triplet-ground state with a negative $\Delta E_{S T}$ value $(-1.8 \mathrm{kcal}$ $\mathrm{mol}^{-1}$ ) calculated at the $\operatorname{CCSD}(\mathrm{T})$ level, indicating such an allmetal cluster is significantly stabilized in the triplet state probably due to the Baird aromaticity.

Same with ${ }^{3} \mathrm{Al}_{4}^{4-}$, both $\mathrm{Be}_{2} \mathrm{~B}_{6}$ and $\mathrm{Be}_{2} \mathrm{~B}_{7}{ }^{+}$have two SOMOs in the 4-electron $\sigma_{\text {rad }}$ System (Fig. 1c and Fig. S1). However, formal electron count is not enough to determine the triplet-state aromaticity of these aluminum or boron clusters as the applicability of Baird's rule in all-metal systems has never been proven before. To verify or falsify the hypothesis of Baird aromaticity in these compounds, we need to apply a set of aromaticity indices. ${ }^{30}$

We first performed an EDDB analysis to quantitatively evaluate the electron delocalization of these systems (Fig. 2). Dissected EDDB results were calculated based on the symmetry of natural orbitals for bond delocalization (NOBDs). As a typical organic Baird aromatic molecule with $4 \pi$-electrons, the $D_{4 h}$ cyclobutadiene $\left({ }^{3} \mathrm{CBD}\right)$ is used here for comparison. The $\pi$ $\operatorname{EDDB}_{\alpha}(2.21 \mathrm{e})$ and $\pi-\operatorname{EDDB}_{\beta}(0.75 \mathrm{e})$ of the triplet CBD show $75 \%$ degree of delocalization in both $\alpha$ and $\beta$ subspaces. To obtain a clearer view of $\pi$-delocalization in ${ }^{3} \mathrm{Li}_{3} \mathrm{Al}_{4}^{-}$and ${ }^{3} \mathrm{Li}_{3} \mathrm{Ga}_{4}{ }^{-}$, we adopted the four- $\mathrm{Li}^{+}$stabilized analogues with more symmetric geometries (Fig. 2). $\pi$-Electron delocalization in the $\mathrm{Al}_{4}{ }^{4-}$ and $\mathrm{Ga}_{4}{ }^{4-}$ moieties of ${ }^{3} \mathrm{Li}_{4} \mathrm{Al}_{4}$ (2.38e) and ${ }^{3} \mathrm{Li}_{4} \mathrm{Ga}_{4}$ (2.33e) are only slightly smaller than that in CBD (2.96e), suggesting that both clusters can be considered as Baird aromatic. In comparison, the
$\pi$-EDDB in the singlet state are much smaller $\left({ }^{1} \mathrm{Li}_{4} \mathrm{Al}_{4}: 0.97 \mathrm{e}\right.$ ${ }^{1} \mathrm{Li}_{4} \mathrm{Ga}_{4}: 0.39 \mathrm{e}$ ) probably due to the $4 \pi$ Hückel antiaromaticity.

In contrast to the above analyzed $\pi$-Baird aromatics, the ${ }^{3} \mathrm{Al}_{4}{ }^{4-}$ appears to have very weak delocalization in the $\sigma_{\mathrm{rad}}$ framework (0.77e). In fact, we classified the two SOMOs of ${ }^{3} \mathrm{Al}_{4}^{4-}$ as $\sigma_{\text {rad }}$ orbitals, but because of their Rydberg character they contribute less than expected to the $\sigma_{\text {rad }}$ delocalization. On the other hand, both ${ }^{3} \mathrm{Be}_{2} \mathrm{~B}_{6}\left(\sigma_{\mathrm{rad}}-\mathrm{EDDB}: 3.00 \mathrm{e}\right)$ and ${ }^{3} \mathrm{Be}_{2} \mathrm{~B}_{7}{ }^{+}\left(\sigma_{\mathrm{rad}}{ }^{-}\right.$ EDDB: 3.15e) can be considered as Baird aromatic (Fig. 2) due to large degrees of delocalization (75\% in ${ }^{3} \mathrm{Be}_{2} \mathrm{~B}_{6}$ and $79 \%$ in $\left.{ }^{3} \mathrm{Be}_{2} \mathrm{~B}_{7}{ }^{+}\right)$. The $\sigma_{\text {rad }}$ EDDB values in the spinless singlet state $\left({ }^{1} \mathrm{Be}_{2} \mathrm{~B}_{6}: 2.78 \mathrm{e} ;{ }^{1} \mathrm{Be}_{2} \mathrm{~B}_{7}{ }^{+}: 2.49 \mathrm{e}\right)$ are only slightly smaller than those in the triplet state, and thus we are unable to deduce the aromaticity reversal simply based on EDDB results.

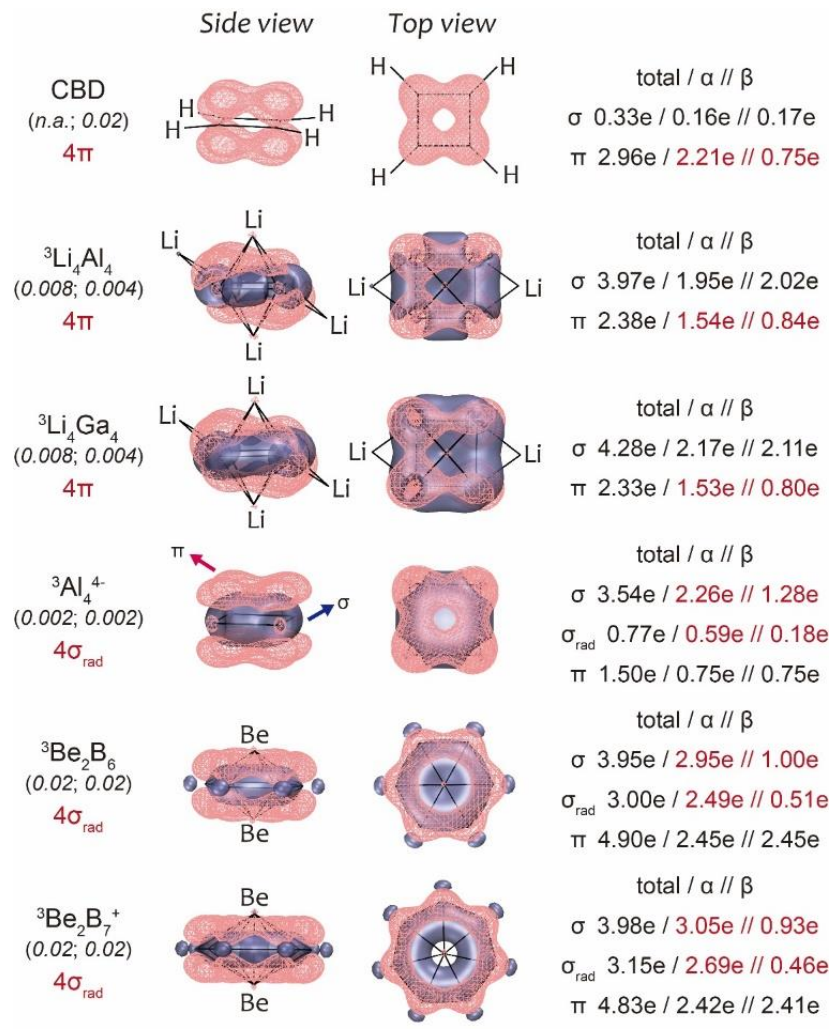

Fig. 2 Dissected EDDB results. Isovalues for $\sigma$-EDDB and $\pi$-EDDB are given in parentheses (iso $o_{\sigma} ;$ iso $O_{\pi}$ ). As the $\sigma_{\mathrm{rad}} \mathrm{NOBDs}$ of ${ }^{3} \mathrm{Li}_{4} \mathrm{Al}_{4}$ and ${ }^{3} \mathrm{Li}_{4} \mathrm{Ga}_{4}$ are less distinct from the rest of the $\sigma$ components, the $\sigma_{\text {rad }}$-EDDB values were not calculated for these two species. Lithium and beryllium cations were not included in the EDDB calculations.

The EDDB analysis did not provide clear evidence for the $\sigma$ Baird aromaticity of ${ }^{3} \mathrm{Al}_{4}^{4-}$, but the normalized $\mathrm{MCl}$ values (Table 1) calculated for the $\sigma_{\text {rad }}$ systems of ${ }^{3} \mathrm{Al}_{4}^{4-}(0.671)$ and ${ }^{1} \mathrm{Al}_{4}^{4-}(-$ 0.527 ) suggest that the naked $\mathrm{Al}_{4}{ }^{4-}$ actually follows the Baird's rule. The $\sigma-\mathrm{MCl}^{1 / n}$ values for $\mathrm{Be}_{2} \mathrm{~B}_{6}$ (singlet: -0.568 ; triplet: 0.627 ) and $\mathrm{Be}_{2} \mathrm{~B}_{7}{ }^{+}$(singlet: -0.580 ; triplet: 0.691 ) indicate that both species follow the Baird's rule, while the $\sigma$-Baird aromaticity exists in the triplet state. The $\pi-\mathrm{MCl}^{1 / n}$ of ${ }^{3} \mathrm{Li}_{3} \mathrm{Al}_{4}$ (0.511) and ${ }^{3} \mathrm{Li}_{3} \mathrm{Ga}_{4}{ }^{-}(0.498)$ are only slightly smaller than that of CBD (0.656). However, the $\pi-\mathrm{MCl}^{1 / n}$ of ${ }^{1} \mathrm{Li}_{3} \mathrm{Al}_{4}{ }^{-}(0.369)$ in the spinless singlet state is not small enough to indicate $\pi$ antiaromaticity, whereas ${ }^{1} \mathrm{Li}_{3} \mathrm{Ga}_{4}$ - has a negative $\pi-\mathrm{MCl}^{1 / n}$ value $(-0.266)$ that supports the aromaticity reversal of $\mathrm{Li}_{3} \mathrm{Ga}_{4}$. 
COMMUNICATION

Table 1. Singlet-triplet energy gaps and $\mathrm{MCl}^{1 / n}$ in the triplet state ${ }^{a}$

\begin{tabular}{|c|c|c|c|c|c|c|c|c|c|}
\hline & $\Delta E_{\mathrm{ST}}{ }^{b}$ & $\sigma_{\text {rad }}$ system ${ }^{d}$ & $\pi$ system ${ }^{d}$ & $\sigma-\mathrm{MCl}_{\alpha}{ }^{1 / n}$ & $\sigma-\mathrm{MCl}^{1 / n}$ & $\sigma-\mathrm{MCl}^{1 / \mathrm{n}}$ & $\pi-\mathrm{MCl}_{\alpha}{ }^{1 / n}$ & $\pi-\mathrm{MCl}_{\beta}{ }^{1 / n}$ & $\pi-\mathrm{MCl}^{1 / n}$ \\
\hline${ }^{3} \mathrm{CBD}$ & $5.9^{c}$ & 1 & Baird (3//1) & 1 & 1 & 1 & 0.666 & 0.646 & 0.656 \\
\hline${ }^{3} \mathrm{Al}_{4}^{4-}$ & 1.6 & Baird (3//1) & Hückel (1//1) & 0.683 & 0.658 & $0.671[-0.527]^{f}$ & 0.658 & 0.658 & $0.658[0.648]^{f}$ \\
\hline${ }^{3} \mathrm{Li}_{3} \mathrm{Al}_{4}^{-}$ & -0.5 & Hückel (1//1) & Baird (3//1) & $0.758^{e}$ & $0.758^{e}$ & $0.758^{c}[0.758]^{f}$ & 0.412 & 0.573 & $0.511[0.369]^{f}$ \\
\hline${ }^{3} \mathrm{Li}_{3} \mathrm{Ga}_{4}-$ & -1.7 & Hückel (1//1) & Baird (3//1) & $0.755^{e}$ & $0.755^{e}$ & $0.755^{c}[0.739]^{f}$ & 0.384 & 0.565 & $0.498[-0.266]^{f}$ \\
\hline${ }^{3} \mathrm{Be}_{2} \mathrm{~B}_{6}$ & -8.2 & Baird $(3 / / 1)$ & Hückel (3//3) & 0.621 & 0.632 & $0.627[-0.568]^{f}$ & 0.597 & 0.596 & $0.596[0.548]^{f}$ \\
\hline${ }^{3} \mathrm{Be}_{2} \mathrm{~B}_{7}^{+}$ & -12.6 & Baird $(3 / / 1)$ & Hückel (3//3) & 0.655 & 0.719 & $0.691[-0.580]^{f}$ & 0.636 & 0.636 & $0.636[0.555]^{f}$ \\
\hline
\end{tabular}

${ }^{a}$ For $\mathrm{CBD}, \mathrm{Al}_{4}^{4-}, \mathrm{Li}_{4} \mathrm{Al}_{4}$, and $\mathrm{Li}_{4} \mathrm{Ga}_{4}, n=4$; for $\mathrm{Be}_{2} \mathrm{~B}_{6}, n=6$; for $\mathrm{Be}_{2} \mathrm{~B}_{7}{ }^{+}, n=7$. ${ }^{b} \Delta E_{\mathrm{ST}}$ values at the $\mathrm{B} 3 \mathrm{LYP}$ level are given in kcal mol ${ }^{-1}$ while those at the CCSD(T) level are provided in Table S1 in the ESI. ${ }^{~} \mathrm{CCSD}(\mathrm{T})$ value is $11.9 \mathrm{kcal} \mathrm{mol}^{-1}$ and experimental value for the tetrakis(trimethylsilyl)cyclobuta-1,3-diene species is $13.9 \mathrm{kcal}$ mol-1.31 $d(m / / n)$ means that the system has $m \alpha$ and $n \beta$ electrons. ${ }^{e}$ The given $\sigma-\mathrm{MCl}$ values of $\mathrm{Li}_{3} \mathrm{Al}_{4}{ }^{-}$and $\mathrm{Li}_{3} \mathrm{Ga}_{4}{ }^{-}$were calculated with contributions from inseparable $\sigma_{\text {rad }}$ and $\sigma_{\text {tan }}$ systems, whereas for the rest of the species only the $\sigma_{\text {rad }}$ system was considered. ${ }^{f} \mathrm{The}_{\mathrm{MCl}}{ }^{1 / n}$ values in the spinless singlet state are given in square brackets.

Both $\mathrm{CBD}$ and ${ }^{3} \mathrm{Al}_{4}{ }^{4-}$ possess the shielding cones covering the four-membered rings (4MRs) and the surrounding deshielding loops, which are characteristic of aromatic systems. ${ }^{32}$ Regardless, the ICSS plot of ${ }^{3} \mathrm{Al}_{4}^{4-}$ does not help determine whether there is Baird aromaticity in the $\sigma_{\text {rad }}$ system because the species is already Hückel aromatic in both $\sigma_{\tan }$ and $\pi$ systems. Interestingly, a deshielding loop and a deshielding cone coexist in the ${ }^{1} \mathrm{Li}_{3} \mathrm{Al}_{4}{ }^{-}$which has conflicting aromatic characters. The double $\sigma$-Hückel aromaticity is dominant in the formation of the deshielding loop, while the deshielding cone is indicative of antiaromaticity which can only results from the $4 \pi$ system of ${ }^{1} \mathrm{Li}_{3} \mathrm{Al}_{4}$. The $\mathrm{HOMO}$ of ${ }^{1} \mathrm{Li}_{3} \mathrm{Al}_{4}{ }^{-}$has 0.29 electrons of backdonation from $\mathrm{Li}_{3}{ }^{3+}$ to the $4 \mathrm{MR}$, which is absent in ${ }^{1} \mathrm{Li}_{3} \mathrm{Ga}_{4}{ }^{-}$(Fig. S2). Such difference could explain why the $\pi$-antiaromatic character of ${ }^{1} \mathrm{Li}_{3} \mathrm{Al}_{4}{ }^{-}$is relatively weaker than that of ${ }^{1} \mathrm{Li}_{3} \mathrm{Ga}_{4}{ }^{-}$which can no longer uphold the rectangular $4 \mathrm{MR}$ (see Fig. S3), accounting for the distinct $\pi-\mathrm{MCl}^{1 / n}$ values $\left({ }^{1} \mathrm{Li}_{3} \mathrm{Al}_{4}: 0.369 ;{ }^{1} \mathrm{Li}_{3} \mathrm{Ga}_{4}:-0.266\right)$. The ICSS plots of $\mathrm{Be}_{2} \mathrm{~B}_{6}$ and $\mathrm{Be}_{2} \mathrm{~B}_{7}+$ indicate antiaromaticity in the spinless singlet state and aromaticity in the triplet ground state.
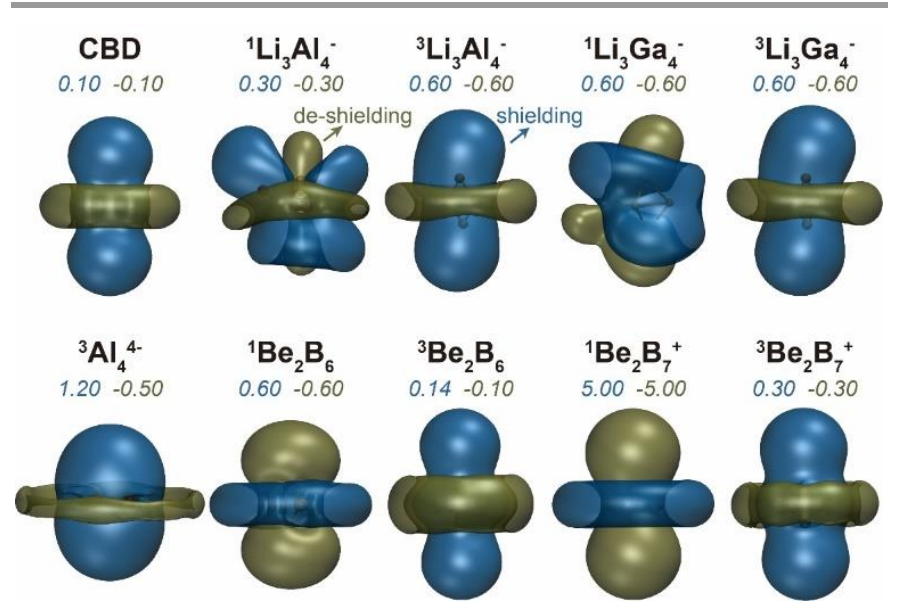

Fig. 3 ICSS plots for CBD and a series of all-metal clusters. Varying isovalues given in italic were used for the optimal display of shielding (blue) and de-shielding (tan) surfaces.
Hence, aromatic characters of a series of all-metal clusters in the lowest-lying triplet state evaluated via EDDB, $\mathrm{MCl}$, and ICSS analyses have been discussed in this study. We proved the $\pi$-Baird aromaticity of ${ }^{3} \mathrm{Li}_{3} \mathrm{Al}_{4}{ }^{-}$and ${ }^{3} \mathrm{Li}_{3} \mathrm{Ga}_{4}-$ as well as the $\sigma$-Baird aromaticity of ${ }^{3} \mathrm{Be}_{2} \mathrm{~B}_{6}$ and ${ }^{3} \mathrm{Be}_{2} \mathrm{~B}_{7}{ }^{+}$. Moreover, $\mathrm{Li}_{3} \mathrm{Ga}_{4}{ }^{-}, \mathrm{Be}_{2} \mathrm{~B}_{6}$, and $\mathrm{Be}_{2} \mathrm{~B}_{7}^{+}$are triplet ground state species due to significant stabilization from Baird aromaticity. For the first time, we demonstrated that all-metal species can also follow the Baird's rule. Our findings expand the scope of Baird's rule and open up an avenue to the study of all-metal Baird aromatics.

This work was supported with funds from the China Scholarship Council (CSC) by a State Scholarship Fund (No. 201906310040, D.C.), the National Science Foundation of China (21573179, J.Z.), the Top-Notch Young Talents Program of China (J.Z.), the Ministerio de Economía y Competitividad (MINECO) of Spain (project CTQ2017-85341-P, M.S.), and the Generalitat de Catalunya (project 2017SGR39, M.S.). D.W.S. acknowledges the financial support by the European Union's Framework Programme for Research and Innovation Horizon 2020 (20142020) under the Marie Skłodowska-Curie Grant Agreement No. 797335 "MulArEffect".

\section{Conflicts of interest}

There are no conflicts to declare.

\section{Notes and references}

¥ DFT calculations were carried out using the Gaussian 09 software package. ${ }^{33}$ Geometries were optimized at the (U)B3LYP level with the aug-cc-pVTZ basis set for $\mathrm{C}, \mathrm{H}, \mathrm{Li}, \mathrm{Al}, \mathrm{Be}$, and $\mathrm{B}$ atoms and the aug-cc-pVTZ-PP basis set ${ }^{34,35}$ for $\mathrm{Ga}$ atoms. Exceptionally, the $6-311+\mathrm{G}(\mathrm{d})$ basis set was used for the naked $\mathrm{Al}_{4}{ }^{4-}$ cluster. ${ }^{36}$ These basis sets were also used in EDDB and $\mathrm{MCl}$ analyses at the (U)CAM-B3LYP level. ${ }^{37,} 38$ A less expensive method, (U)B3LYP/631G(d) LanL2DZ (LanL2DZ for Ga and 6-31G(d) for the rest atoms), was adopted in the ICSS calculations using the gauge 
invariant atomic orbitals (GIAO) method. The Multiwfn program ${ }^{39}$ was used to calculated the ICSS. The RunEDDB script program ${ }^{40}$ was used for EDDB analyses. The EDDB function evaluates only the local resonance while the $E D_{D B}$ function also includes external resonance effects. We used $E{ }^{2} B_{E}$ instead of $E D D B_{F}$ for $\mathrm{Al}_{4}, \mathrm{Ga}_{4}, \mathrm{~B}_{6}$, and $\mathrm{B}_{7}$ fragments in cation-stabilized systems. The $\mathrm{MCl}$ analyses were performed using the AIMALL and ESI-3D programs. ${ }^{41-45}$ The CYLview ${ }^{46}$ and $\mathrm{VMD}^{47}$ programs were used for the visualization of optimized structures, EDDB, and ICSS surfaces.

1. E. Hückel, Z. Phys., 1931, 70, 204-286.

2. N. C. Baird, J. Am. Chem. Soc., 1972, 94, 4941-4948.

3. E. Heilbronner, Tetrahedron Lett., 1964, 5, 1923-1928.

4. J.-i. Aihara, B. Chem. Soc. Jpn., 1978, 51, 1788-1792.

5. P. Schleyer, J. I. Wu, F. P. Cossio and I. Fernandez, Chem Soc. Rev., 2014, 43, 4909-4921.

6. H. Ottosson, Nat. Chem., 2012, 4, 969-971.

7. M. Rosenberg, C. Dahlstrand, K. Kilså and H. Ottosson, Chem. Rev., 2014, 114, 5379-5425.

8. R. K. Mohamed, S. Mondal, K. Jorner, T. F. Delgado, V. V. Lobodin, H. Ottosson and I. V. Alabugin, J. Am. Chem. Soc., 2015, 137, 15441-15450.

9. R. Papadakis and H. Ottosson, Chem. Soc. Rev., 2015, 44 6472-6493.

10. K. Jorner, F. Feixas, R. Ayub, R. Lindh, M. Solà and H. Ottosson, Chem. -Eur. J., 2016, 22, 2793-2800.

11. R. Papadakis, H. Li, J. Bergman, A. Lundstedt, K. Jorner, R. Ayub, S. Haldar, B. O. Jahn, A. Denisova, B. Zietz, R. Lindh, B. Sanyal, H. Grennberg, K. Leifer and H. Ottosson, Nat. Commun., 2016, 7, 12962.

12. M. Ueda, K. Jorner, Y. M. Sung, T. Mori, Q. Xiao, D. Kim, H. Ottosson, T. Aida and Y. Itoh, Nat. Commun., 2017, 8, 346. O. El Bakouri, J. R. Smith and H. Ottosson, J. Am. Chem. Soc., 2020, 142, 5602-5617.

14. C. A. Tsipis, Coord. Chem. Rev., 2005, 249, 2740-2762.

15. A. I. Boldyrev and L.-S. Wang, Chem. Rev., 2005, 105, 3716-3757.

16. A. E. Kuznetsov, K. A. Birch, A. I. Boldyrev, X. Li, H.-J. Zhai and L.-S. Wang, Science, 2003, 300, 622-625.

17. X. Li, A. E. Kuznetsov, H.-F. Zhang, A. I. Boldyrev and L.-S. Wang, Science, 2001, 291, 859

18. Y.-J. Wang, C.-Q. Miao, J.-J. Xie, Y.-R. Wei and G.-M. Ren, New J. Chem., 2019, 43, 15979-15982.

19. T. Shen, D. Chen, L. Lin and J. Zhu, J. Am. Chem. Soc., 2019, 141, 5720-5727.

$20 . \quad$ D. W. Szczepanik, M. Andrzejak, K. Dyduch, E. Zak, M. Makowski, G. Mazur and J. Mrozek, Phys. Chem. Chem. Phys., 2014, 16, 20514-20523.

21. P. Bultinck, R. Ponec and S. Van Damme, J. Phys. Org Chem., 2005, 18, 706-718.

22. F. Feixas, E. Matito, J. Poater and M. Solà, Chem. Soc. Rev. 2015, 44, 6434-6451.

23. F. Feixas, J. O. C. Jiménez-Halla, E. Matito, J. Poater and M. Solà, J. Chem. Theor. Comput., 2010, 6, 1118-1130. M. Giambiagi, M. Segre de Giambiagi, C. D. dos Santos Silva and A. Paiva de Figueiredo, Phys. Chem. Chem. Phys., 2000, 2, 3381-3392.

25. R. F. W. Bader, Chem. Rev., 1991, 91, 893-928.

26. R. F. W. Bader, Atoms in Molecules - A Quantum Theory, Oxford University Press, Oxford, 1990.
28.

29.

30.

31.

39.

40.

41.

46.

47.
J. O. Jiménez-Halla, E. Matito, L. Blancafort, J. Robles and M. Solà, J. Comput. Chem., 2009, 30, 2764-2776.

J. O. Jiménez-Halla, E. Matito, L. Blancafort, J. Robles and M. Solà, J. Comput. Chem., 2011, 32, 372-373.

M. Solà, Front. Chem., 2017, 5, 22.

A. Kostenko, B. Tumanskii, Y. Kobayashi, M. Nakamoto, A. Sekiguchi and Y. Apeloig, Angew. Chem. Int. Ed., 2017, 56, 10183-10187.

A. Muñoz-Castro, Phys. Chem. Chem. Phys., 2017, 19, 12633-12636.

M. J. Frisch, G. W. Trucks, H. B. Schlegel, G. E. Scuseria, M. A. Robb, J. R. Cheeseman, G. Scalmani, V. Barone, B.

Mennucci, G. A. Petersson, H. Nakatsuji, M. Caricato, X. Li, H. P. Hratchian, A. F. Izmaylov, J. Bloino, G. Zheng, J. L. Sonnenberg, M. Hada, M. Ehara, K. Toyota, R. Fukuda, J. Hasegawa, M. Ishida, T. Nakajima, Y. Honda, O. Kitao, H. Nakai, T. Vreven, J. A. Montgomery, J. E. Peralta, F. Ogliaro, M. Bearpark, J. J. Heyd, E. Brothers, K. N. Kudin, V. N. Staroverov, R. Kobayashi, J. Normand, K. Raghavachari, A. Rendell, J. C. Burant, S. S. lyengar, J. Tomasi, M. Cossi, N. Rega, J. M. Millam, M. Klene, J. E. Knox, J. B. Cross, V. Bakken, C. Adamo, J. Jaramillo, R. Gomperts, R. E. Stratmann, O. Yazyev, A. J. Austin, R. Cammi, C. Pomelli, J. W. Ochterski, R. L. Martin, K. Morokuma, V. G. Zakrzewski, G. A. Voth, P. Salvador, J. J. Dannenberg, S. Dapprich, A. D. Daniels, Ö. Farkas, J. B. Foresman, J. V. Ortiz, J. Cioslowski and D. J. Fox, Gaussian 09, Revision E.01, Gaussian, Inc., Wallingford CT, 2013. K. A. Peterson, D. Figgen, E. Goll, H. Stoll and M. Dolg, J. Chem. Phys., 2003, 119, 11113-11123.

K. A. Peterson, B. C. Shepler, D. Figgen and H. Stoll, J. Phys. Chem. A, 2006, 110, 13877-13883.

D. Y. Zubarev and A. I. Boldyrev, J. Phys. Chem. A, 2008 112, 7984-7985.

T. Yanai, D. P. Tew and N. C. Handy, Chem. Phys. Lett., 2004, 393, 51-57.

.W. Szczepanik, M. Solà, M. Andrzejak, B. Pawelek, J. Dominikowska, M. Kukulka, K. Dyduch, T. M. Krygowsk and H. Szatylowicz, J. Comput. Chem., 2017, 38, 16401654.

T. Lu and F. Chen, J. Comput. Chem., 2012, 33, 580-592.

D. W. Szczepanik, RunEDDB, available at: http://eddb.pl/runeddb/ (accessed in April 2020).

E. Matito, ESI-3D: Electron Sharing Indices Program for 3D Molecular Space Partitioning. Institute of Computational chemistry and Catalysis (IQCC), University of Girona, Catalonia, Spain, 2006; http://iqcc.udg.edu/ eduard/ESI/, 2006.

T. A. Keith, Aimall (version 14.06.21), TK Gristmill Software, Overland Park KS, USA (aim.tkgristmill.com), 2014.

E. Matito, M. Duran and M. Solà, J. Chem. Phys., 2004, 122, 014109.

E. Matito, M. Duran and M. Solà, J. Chem. Phys., 2006, 125, 059901.

E. Matito, M. Solà, P. Salvador and M. Duran, Faraday Discuss., 2007, 135, 325-345.

C. Y. Legault, CYLview, 1.0b, Université de Sherbrooke, 2009 (http://www.cylview.org).

W. Humphrey, A. Dalke and K. Schulten, J. Mol. Graphics, 1996, 14, 33-38. 
TABLE OF CONTENTS

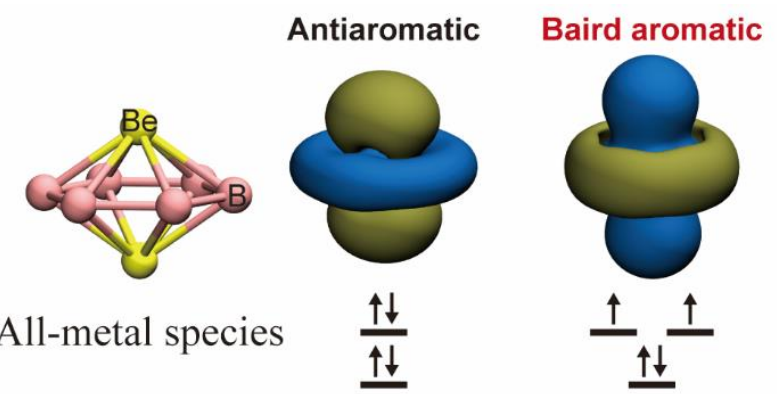

We have proven that the Baird's rule can be also applied to a series of all-metal species with both $\sigma$ - and $\pi$-aromaticity 